\title{
Uterine carcinosarcoma with extensive extrauterine component
}

\author{
Pedro Carvalho Almeida, Luís Amaral Ferreira, Paulo Donato
}

Medical Imaging Department, Centro Hospitalar e Universitário de Coimbra EPE, Coimbra, Portugal

\section{Correspondence to} Dr Pedro Carvalho Almeida; pedroalmeida.pmca@gmail.com

Accepted 16 November 2021

\section{DESCRIPTION}

A 58-year-old postmenopausal woman presented to the emergency department with complaints of abdominal pain for the past 2 weeks. Previous screening for cervical cancer had not been performed.

Transabdominal ultrasonography revealed a mass of heterogeneous echogenicity in the periumbilical region, $14 \mathrm{~cm}$ long.

Contrast-enhanced multidetector CT was performed for further characterisation. It showed a lobulated, ill-defined, heterogeneous mass, measuring $19 \times 14 \times 9 \mathrm{~cm}$, originating from the uterine corpus. This lesion had an extensive extrauterine component, displaying contrastenhancing portions and significant central necrosis (figure 1A-C). An organised liquid collection with gas and parietal enhancement, suggestive of an abscess, was surrounding the tumour (figure 1C). The lesion caused deviation, invasion and perforation of bowel loops with evident pneumoperitoneum (figure 1D). It showed no signs of bowel obstruction or hydronephrosis.

Abdominopelvic MRI was performed and showed a mass arising from the endometrial cavity, invading the myometrium and extending into the abdominal cavity. The solid areas showed highsignal intensity on diffusion-weighted imaging with corresponding reduced apparent diffusion coefficient (ADC) values, compatible with restricted diffusion (figure 2A,B). At T2-weighted there was a heterogeneous high-signal intensity with central necrosis (figure 2C). Based on the conjunction of imaging features, a malignant nature was foreseen and an endometrial biopsy was performed. Unfortunately, the material obtained was insufficient

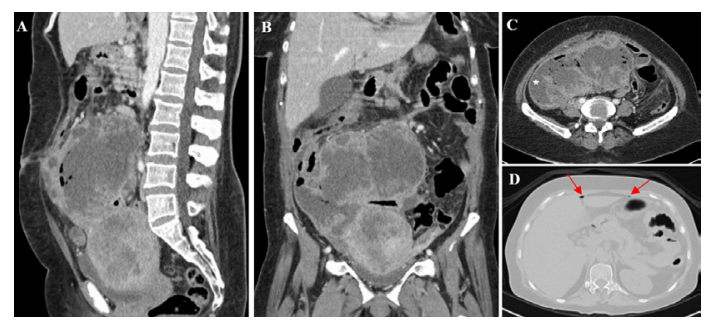

(c) BMJ Publishing Group Limited 2021. No commercial re-use. See rights and permissions. Published by BMJ.

\begin{tabular}{|l|}
\hline To cite: Almeida PC, \\
Amaral Ferreira L, \\
Donato P. BMJ Case \\
Rep 2021;14:e247643. \\
doi:10.1136/bcr-2021- \\
247643 \\
\hline
\end{tabular}
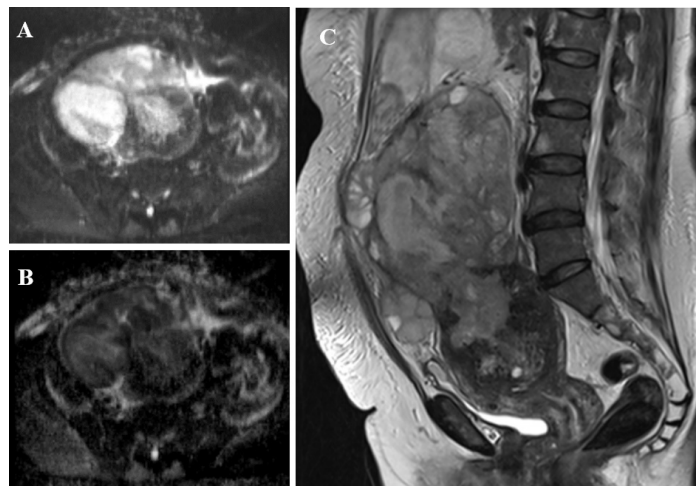

Figure 2 (A) Diffusion-weighted imaging (DWI) at B $700 \mathrm{~s} / \mathrm{mm}^{2}$ shows an abdominal mass with hyperintense signal, suggesting restricted diffusion of water molecules.

(B) Corresponding apparent diffusion coefficient (ADC) map for quantification of diffusion restriction demonstrate low ADC value. (C) Sagittal T2-weighted image reveals a mass with heterogeneous highsignal intensity with central necrosis, arising from the endometrial cavity into the peritoneal cavity.

and, after discussion in multidisciplinary reunion, a surgery was scheduled. Radical hysterectomy, bilateral salpingo-oophorectomy, resection of a segment of the distal ileum and right colon with ileocolonic anastomosis, infracolic omentectomy and a paraaortic lymphadenectomy were performed. The procedure was uneventful. The anatomopathological study revealed a uterine carcinosarcoma with direct invasion of distal ileum and ascending colon, and paraaortic lymph node metastasis-FIGO (International Federation of Gynaecology and Obstetrics) stage IVB.

At 6-month follow-up CT scan, abdominal lymphadenopathies and peritoneal implants were present.

Uterine carcinosarcomas, formerly called malignant mixed Müllerian tumours, are rare and aggressive cancers. They comprise less than $5 \%$ of all uterine tumours but account for $16.4 \%$ of all deaths from uterine malignancy. ${ }^{1}$ Carcinosarcoma is characterised by a combination of carcinomatous (epithelial) and sarcomatous (mesenchymal) elements. ${ }^{23}$ As the epithelial element is the mainly responsible for most metastasis and vascular invasion, uterine carcinosarcoma has been reclassified as a metaplastic form of endometrial carcinoma. ${ }^{3}$ However, since it behaves more aggressively, carcinosarcoma is still included in uterine sarcomas studies, as well as in the separate section of 'mixed epithelial and mesenchymal tumours' of 2014 WHO classification. ${ }^{4}$ These tumours tend to occur in postmenopausal 
women, and most of them present with abnormal vaginal bleeding, pelvic pain and uterine enlargement. ${ }^{5}$ At presentation, extrauterine spread (FIGO stages III-IV) is found in up to onethird of cases. ${ }^{5}$ The diagnosis is histological, and sometimes only possible after hysterectomy. ${ }^{3}$ Appropriate treatment includes total abdominal hysterectomy, bilateral salpingo-oophorectomy,

\section{Patient's perspective}

I am very thankful to all the healthcare professionals who gave me good treatment and care. Also, I am grateful that my case helps the scientific community and other patients with the same problem as me.

\section{Learning points}

- Uterine carcinosarcomas are rare and highly aggressive tumours in which extrauterine spread is found in up to onethird of cases at presentation.

- Given the aggressive nature of uterine carcinosarcomas, timely detection using characteristic imaging and pathological findings is critical to improving survival.

- Surgery remains the main treatment for these patients and, as they are at increased risk of local recurrence and distant metastasis, close follow-up is indicated. removal of pelvic and aortic lymph nodes, and omentectomy. ${ }^{25}$ Adjuvant treatment following surgical resection is based on the stage at diagnosis, and combined chemotherapy appears to result in fewer recurrences than whole-body irradiation. ${ }^{4}$ Follow-up should be determined by the risk of recurrence, which is relatively common in these patients.

Contributors PCA contributed to the design and writing the manuscript; LAF and PD provided supervision, critical review and final approval.

Funding The authors have not declared a specific grant for this research from any funding agency in the public, commercial or not-for-profit sectors.

Competing interests None declared.

Patient consent for publication Consent obtained directly from patient(s).

Provenance and peer review Not commissioned; externally peer reviewed.

Case reports provide a valuable learning resource for the scientific community and can indicate areas of interest for future research. They should not be used in isolation to guide treatment choices or public health policy.

\section{REFERENCES}

1 Kanthan R, Senger J-L. Uterine Carcinosarcomas (malignant mixed Müllerian tumours): a review with special emphasis on the controversies in management. Obstet Gynecol Int 2011;2011:1-13.

2 Kobayashi H, Uekuri C, Akasaka J, et al. The biology of uterine sarcomas: a review and update. Mol Clin Oncol 2013;1:599-609.

3 El-nashar SA, Mariani A. Uterine carcinosarcoma. Clin Obs Gynecol 2011;54:292-304.

4 Mbatani N, Olawaiye AB, Prat J. Uterine sarcomas. Int J Gynecol Obstet 2018;143:51-8.

5 D'Angelo E, Prat J. Uterine sarcomas: a review. Gynecol Oncol 2010;116:131-9.

Copyright 2021 BMJ Publishing Group. All rights reserved. For permission to reuse any of this content visit

https://www.bmj.com/company/products-services/rights-and-licensing/permissions/

BMJ Case Report Fellows may re-use this article for personal use and teaching without any further permission.

Become a Fellow of BMJ Case Reports today and you can:

- Submit as many cases as you like

- Enjoy fast sympathetic peer review and rapid publication of accepted articles

- Access all the published articles

- Re-use any of the published material for personal use and teaching without further permission

Customer Service

If you have any further queries about your subscription, please contact our customer services team on +44 (0) 2071111105 or via email at support@bmj.com.

Visit casereports.bmj.com for more articles like this and to become a Fellow 